\title{
Control of Nickel Alloy Structural Change by the Atomic Emission Spectroscopy Method
}

\author{
Nina Molchan', Dmitriy Eliseev², Valery Fertikov² \\ ${ }^{1}$ Quality Control Department, FSUE SPC "Pharmzaschita”, Khimki, Russia \\ ${ }^{2}$ Test Center, OJS “VILS”, Moscow, Russia \\ Email: nimolchan@mail.ru, fertikovvalerii@mail.ru
}

How to cite this paper: Molchan, N., Eliseev, D. and Fertikov, V. (2016) Control of Nickel Alloy Structural Change by the Atomic Emission Spectroscopy Method. American Journal of Analytical Chemistry, 7, 633-641.

http://dx.doi.org/10.4236/ajac.2016.79059

Received: July 25, 2016

Accepted: August 23, 2016

Published: August 26, 2016

Copyright $\odot 2016$ by authors and Scientific Research Publishing Inc. This work is licensed under the Creative Commons Attribution International License (CC BY 4.0).

http://creativecommons.org/licenses/by/4.0/

\begin{abstract}
The aim of the work was the assessment of capability for the change control in the structure of a compact material of pelletized heatproof nickel alloy grade EP741NP using the atomic emission method. The proposed method of evaluation is based on the statistical significance of the analytical response differences during atomic emission spectroscopy of solid specimens taken from one sample before and after heat treatment using the instruments AtomComp 81 and ARL 4460 with a high-voltage spark excitation. For calculations, the ratio of the line intensity of the analyzed element to the line intensity of the main sample component (in our case $\mathrm{Ni}_{2254}$ ) was used. The difference confidence estimation was made by the averages comparison method in a variance analysis. The study results are presented on the effect of material structure on analytical response during atomic emission spectroscopy of solid specimens. It was proved that the samples before and after heat treatment give statistically differing results while analyzed.
\end{abstract}

\section{Keywords}

Atomic Emission Spectral Analysis, Pelletized Heatproof Nickel Alloy, Structure

\section{Introduction}

The necessity of improvement of the existing analysis methods of heatproof nickel alloys and the development of more informative techniques based on new principles is associated with the rising material quality control requirements.

The method of alloy structure control using atomic emission spectroscopy protected by patents [1]-[6], is one of the trends. In the modern sense of the structure of matter, the material structure presents a hierarchically associated sequence of substructures.

In the work [7] an attempt was made to present the single multilevel material struc- 
ture model and the electronic nuclear structure as one of its sublevels.

In the work [8] through the example of sulfides the correlation between thermodynamic parameters and electron concentration change was considered reflecting the relationship between different components of chemical compounds.

In the work [9] through the example of aluminum alloys the effect of the material structure on the result of the chemical analysis of solid samples by the atomic emission spectral analysis (AESA) was shown. A similar approach was used for a titanium alloy [10].

In the presented work the study continuation on the alloy structure change through the example of compacted samples of pelletized heatproof nickel alloy grade EP741NP using the atomic emission spectroscopy method, is considered.

The effect of the structure on an analytical signal was considered in $60-80^{\text {th }}$ of the previous century as an obstructive factor for carrying out chemical analysis [11].

The aim of the present work was the assessment of capability for the change control in the structure of a compact material of pelletized heatproof nickel alloy grade EP741NP using the atomic emission method.

\section{Theoretical}

Depending on a scale, a structure can be considered on several levels, starting from a subatomic (as, for instance, when considering electric and magnetic properties), atomic (when considering crystalline materials), molecular (for example, when considering polymers) and ending finally with microscopic and macroscopic scales [12].

The structural parameters recorded by means of different instrumental methods are more illustrative, diverse and more accessible for analysis than calorimetric parameters. The latter are vaguer, more difficult for interpretation and present the structure as a causal characteristic.

In the present work the structure is considered in terms of the elemental and energetic system component. Therefore the structure of a hardened and annealed material at the equal chemical composition differs in accumulated and dissipated energy level.

When analyzing the samples of the same chemical composition in equal excitation conditions, by changing their structural relation using thermal treatment, it is possible to get statistically differing analytical signals with possibility of their interpretation.

Usually it made to take measures to avoid the effect of the material structure influence on the analytical signal with AESA. Thus, for example, in the Instruction for use of $30^{\text {th }}$ reference standard set for spectral analysis of steel types R9, R18, issued by the Laboratory of Standard Samples of the Iron and Steel Board (Sverdlovsk, 1958), the Item 1 stated: "In the study, the significant effects of 'third' elements, structure and preparation technology on the determination results with the variation of the analysis conditions, were established. Therefore, when performing an analysis using the spark excitation method, it is necessary to adhere to the recommendations of the present practice. During the use of the practice the said effects are the least intense".

The Item 2 of the document stated: "The mentioned reference standards exposed to 
different thermal treatment (hardening, tamper hardening and annealing) give mutually distinct results during spectral analysis using arc excitation. Therefore the $30^{\text {th }}$ set reference standard can be used only for annealed metal analysis during silicon determination [13].

Different ways were used to eliminate this effect [14] [15].

In the present work the same effect is used to characterize the structural state of a nickel alloy and is considered as expanding the informational capabilities of AESA.

The described phenomenon is based on the concept that the structure of any material on the level of interatomic interaction is the function of chemical composition and the internal energy of the system.

During heat treatment of a metal the general chemical composition of the material does not change. The changes of properties distinguishing a heat treated material from an untreated one are due to diffusion processes and microstructural transitions associated with dispersive and carboboride hardening in pelletized heatproof nickel alloys which are accompanying by the change in the energy content of the system.

The energy content of a system is defined in thermodynamics as $U=G+T S$ and consists of the entropic part (TS) and the Gibbs energy (G) dependent on chemical potential of the system atoms and the amount of a substance [16].

The dispersion of a molten metal in an inert atmosphere leads to its quick supercooling and the fixation of a thermodynamically non-equilibrium state which causes the high content of internal energy, so called high entropy state. At the same time, when performing the annealing of a thermodynamically non-equilibrium material, energy dispersion (dissipation) occurs and the material acquires a new more thermodynamically equilibrium structure.

\section{Experimental Techniques}

Compact samples of pelletized heatproof nickel alloy grade EP741NP were used to find the effect of the structure on the atomic emission analysis

Six specimens $15 \times 15 \times 15 \mathrm{~mm}$ size were cut out of a sample and divided into two groups with three specimens each. This amount of samples allowed to statistically guarantee that the entire original sample is presented authentically.

The surfaces of the specimens were polished by grinding machine to get clean surfaces. All six specimens were exposed to atomic emission spectral analysis to get the line intensities of the chemical elements forming a nickel alloy using the AtomComp 81 instrument with high voltage spark excitation.

The said instrument AtomComp 81 (produced by Thermo Jarrel AshCorp.) is a direct reading emission spectrometer and is equipped with the Pashen-Runge optical system with the focal distance $0.75 \mathrm{~m}$.

Hamamatsu photomultipliers with side window diameter $13 \mathrm{~mm}$ are used as detectors. In case of sparking the specimens are blown with argon. The precalcination time is $2 \mathrm{~s}$, the calcination time is $15 \mathrm{~s}$.

The instrument generator operates on the thyratrone $5 \mathrm{C} 22$. The spark polarity is 
monodirectional. The source performs two functions:

a) it evaporates a specimen into a vapor consisting primarily of free atoms and ions;

b) makes the vapor to emit radiation characterizing the type and the number of atoms constituting the vapor.

To reduce the effect of the excitation condition fluctuations on the analysis element line intensity a comparing element was used. In this case the ratio $\mathrm{I}_{\text {an }} / \mathrm{I}_{\text {com }}$ served as an analytical signal,

where $I_{a n}$ : The analysis element analytical line intensity;

$I_{\text {com: }}$ : Spectral line intensity of the comparing element.

The line belonging to the main component of the sample was taken as the reference line, in this case $\mathrm{Ni}_{2254}$.

The measurement series was performed so that each result from the first group specimen alternated with the second group specimen. The analysis results of all six pairs of measurements of two specimens for all elements of the pelletized heatproof nickel alloy grade EP741NP were consistent within the method error which proves the uniformity and indistinguishability of the specimens. Doing so eliminates the possibility of suspecting the instrument drift.

One group is randomly selected of the two groups, exposed to heat treatment (HT) at the temperature $1000^{\circ} \mathrm{C}$ for 10 hours and then cooled in a furnace (annealing).

The two specimen groups (heat treated and not heat treated) again undergo the atomic emission spectral analysis using the instrument AtomComp 81. The specimens are alternated in the sequence: "initial", "annealed" etc.

Relative intensities were determined for aluminum, zirconium, ferrum, silicon, magnesium, manganese, chrome, titanium, niobium and cobalt.

The relative intensities were recorded for the lines: $\mathrm{Al}_{2567}, \mathrm{Al}_{3961}, \mathrm{Zr}_{3496}, \mathrm{Zr}_{3542}, \mathrm{Fe}_{2599}$, $\mathrm{Si}_{2516}, \mathrm{Si}_{3905}, \mathrm{Mg}_{2795}, \mathrm{Mg}_{3832}, \mathrm{Mg}_{2777}, \mathrm{Mr}_{2933}, \mathrm{Cr}_{2989}, \mathrm{Cr}_{4254}, \mathrm{Ti}_{3373}, \mathrm{Nb}_{3195}$ and $\mathrm{Co}_{2286}$.

Also the line intensity from the matrix element (nickel) was recorded. For each analytical line 6 intensity values were collected. The intensities were divided into paired groups for heat treated and initial specimens. The groups were treated mathematically before and after the heat treatment.

Thus the proposed method of assessing structural changes of a pelletized heatproof nickel alloy using spectral analysis includes a division of the randomized sample into two parts, heat treatment of one of these parts and the statistical evaluation of the significance of differences of the analytical signal initial and heat-treated samples.

\section{Results and Discussion}

The mathematical treatment of the results was made by the method of comparison of averages accepted in the variance analysis and, using the Fisher test, the conclusion was drawn on what elements in the present alloy changed their interaction with the matrix element (nickel).

In table the mean values $(\bar{X})$ and the variance $\left(\mathrm{s}^{2}\right)$ for the measurement results $\mathrm{I}_{\text {an }} / \mathrm{I}_{\text {com }}\left(\mathrm{I}_{\text {com }}\right.$-line intensity of $\left.\mathrm{Ni}_{2254}\right)$ of the studied specimens in the initial (IS) and an- 
nealed (AS) state and the calculated values of the Fisher test (F) are presented.

It must be noted that for the 6 pairs the critical Fisher value [17] at the confidence figure 0.95 is equal 4.96 and at the confidence figure 0.99 is equal 10.04 . Under the critical value the specimens are considered to be indistinguishable.

The different lines of the same chemical element have different sensitivity to structural change. For example, it is apparent that the line of $\mathrm{Al}_{2567}$ is far more sensitive to the nickel alloy structural change than the line of $\mathrm{Al}_{3961}$.

The $\mathrm{Mg}_{2777}$ line is far more sensitive to the given nickel alloy structural change than the lines of $\mathrm{Mg}_{2795}$ and $\mathrm{Mg}_{3832}$.

The line $\mathrm{Cr}_{2989}$ line is far more sensitive to the given nickel alloy structural change than the line of $\mathrm{Cr}_{4254}$.

Niobium and cobalt do not respond to given nickel alloy structural change.

The measurements of molybdenum and tungsten were performed using the instrument ARL 4460.

The measurement results showed that after heat treatment the molybdenum intensity increased and tungsten intensity decreased. This can be interpreted as the weakening of the bond of molybdenum with the matrix element (nickel) and the increase of the bond of tungsten with nickel.

The intensity indices of aluminum, vanadium, zirconium, iron, silicon, magnesium, manganese, chrome and titanium after annealing increased which indicates the weakening of the bond of the elements with nickel.

To confirm the stability of the chemical composition of the specimens, additional control was exercised using the inductive couple plasma atomic emission spectroscopy method which is made from a solution and correspondently is no connected with the structural features of the material. In accordance with the analysis results, the identity of chemical composition before and after the heat treatment was confirmed.

It is established that varying the temperature and time of the heat treatment it is possible to detect the movement sequence of the specific chemical elements and to explain the restructuring of the heatproof nickel alloy.

The information obtained by the described method can be used for the control of the state of heatproof nickel alloys in estimating their quality.

The used method of the material quality estimation provides the high accuracy and information content in the control of not only the elemental composition of a heatproof nickel alloy but also of its structure.

The different intensities of the same chemical element have different sensitivity to structural change.

The results presented in Table 1 indicate that annealing strongly changes the original structure.

In the real emission analysis conditions, the dependence between the line intensity and the concentration of an analyzed sample can be frequently disturbed due to different side effects of optical and physical-chemical nature. Therefore, the selection of the conditions of "atomization" (under action of a spark) and measurement of an analytical 
Table 1. The results of comparative analysis of the initial and annealed nickel alloy samples.

\begin{tabular}{cccccc}
\hline & \multicolumn{3}{c}{ Relative intensities of spectral lines and its variance } & \multirow{2}{*}{ F } \\
\cline { 2 - 5 } Lines by elements & $\bar{X}_{I S}$ & $S_{I S}^{2}$ & $\bar{X}_{A S}$ & $S_{A S}^{2}$ & \\
\hline $\mathrm{Al}_{2567}$ & 0.0009 & $6.7 \times 10^{-9}$ & 0.0023 & $4.8 \times 10^{-3}$ & 15.4 \\
$\mathrm{Al}_{3961}$ & 0.0821 & $0.25 \times 10^{-3}$ & 0.1986 & $12.9 \times 10^{-3}$ & $\mathbf{6 . 1 5}$ \\
$\mathrm{Zr}_{3496}$ & 0.0069 & $0.52 \times 10^{-3}$ & 0.0164 & $4.3 \times 10^{-5}$ & $\mathbf{1 2 . 3}$ \\
$\mathrm{Zr}_{3542}$ & 0.0074 & $3.7 \times 10^{-6}$ & 0.0239 & $0.13 \times 10^{-3}$ & 11.9 \\
$\mathrm{Fe}_{2599}$ & 0.0035 & $2.7 \times 10^{-7}$ & 0.0080 & $6.9 \times 10^{-6}$ & 16.4 \\
$\mathrm{Si}_{2516}$ & 0.0032 & $3.9 \times 10^{-8}$ & 0.0066 & $3.7 \times 10^{-6}$ & 19.06 \\
$\mathrm{Si}_{3905}$ & 0.0083 & $7.1 \times 10^{-6}$ & 0.0290 & $0.21 \times 10^{-3}$ & 11.8 \\
$\mathrm{Mg}_{2795}$ & 0.0815 & $0.53 \times 10^{-3}$ & 0.0457 & $1.0 \times 10^{-3}$ & $\mathbf{4 . 9 9}$ \\
$\mathrm{Mg}_{3832}$ & 0.0288 & $7.3 \times 10^{-5}$ & 0.0384 & $0.46 \times 10^{-3}$ & 1.03 \\
$\mathrm{Mg}_{2777}$ & 0.0008 & $6.7 \times 10^{-9}$ & 0.0012 & $8.3 \times 10^{-8}$ & $\mathbf{1 0 . 7}$ \\
$\mathrm{Mn}_{2933}$ & 0.0079 & $2.8 \times 10^{-7}$ & 0.0171 & $3.6 \times 10^{-5}$ & $\mathbf{1 3 . 9}$ \\
$\mathrm{Cr}_{2989}$ & 0.0094 & $1.7 \times 10^{-6}$ & 0.0129 & $3.2 \times 10^{-6}$ & $\mathbf{1 4 . 3 7}$ \\
$\mathrm{Cr}_{4254}$ & 0.0633 & $4.1 \times 10^{-5}$ & 0.069 & $0.24 \times 10^{-3}$ & $\mathbf{0 . 6 9}$ \\
$\mathrm{Ti}_{3373}$ & 0.0188 & $5.0 \times 10^{-6}$ & 0.0400 & $9.3 \times 10^{-5}$ & $\mathbf{2 7 . 5}$ \\
$\mathrm{Nb}_{3195}$ & 0.0183 & $5.1 \times 10^{-7}$ & 0.0242 & $7.7 \times 10^{-5}$ & $\mathbf{2 . 4 7}$ \\
$\mathrm{Co}_{2286}$ & 1.2407 & 0.223 & 1.1692 & 0.104 & $\mathbf{0 . 7 8}$ \\
\hline & & & &
\end{tabular}

signal has the decisive influence on the accuracy and validity of the analysis results.

Previously the authors of works on the spectral analysis of various metals in the form of solid samples pointed out the dependence of obtained results on the physical-chemical features of a sample structure in the sparking zone [11].

During the described processes, the change of the alloying chemical elements interaction with the main matrix element occurs. The analysis of the specimens of one initial blank, part of which undergoes heat treatment during the analysis, provides new information gaining on the specimen structure.

A particular set of spectral lines is characteristic for each chemical element which allows determining the elemental composition of a material through its spectrum. It is widely accepted that the more element content is in a sample the more intense are the lines of the element. However in some cases the line intensities change with an equal chemical composition but a different structure.

Thus, the atomic emission spectrum of a solid sample is not only a function of the chemical composition but also a function of the state i.e. the structure.

The spectrum lines which intensity difference is recorded by the instrument for solid specimens of the same chemical composition but different structure, can characterize the interaction between alloying elements and the matrix.

In case of an identical chemical composition the differences in the properties of ma- 
terials are determined by the differences in their structures which change is limited by a specific range and is caused by the system energy content.

When comparing hardened and annealed specimens it is implied that the hardened material contains more energy than the annealed material (in the form of entropy component).

As for properties, it is evident in the fact that the density of a high temperature structural modification is lower than the low temperature one. Tin and water are exceptions.

Thus, several allotropic modifications are known for iron, and the transition temperature for $\alpha \longrightarrow \gamma$ is $910^{\circ} \mathrm{C}$ and for $\gamma \longrightarrow \delta-1390^{\circ} \mathrm{C}$ [18].

With this, each subsequent modification has a lower density than the previous one and the higher the fixed level of modification the more energy is accumulated by the system.

Titanium in the $\alpha$-form has a density $4.506 \mathrm{~g} / \mathrm{cm}^{3}$ (card 44-1294 [19]), the hightemperature $\beta$-form has a density $4.401 \mathrm{~g} / \mathrm{cm}^{3}$ (card $44-1288$ [19]). The high-temperature $\beta$-titanium accumulates more energy compared with the $\alpha$-form in the form of an entropy component.

Manganese in the $\alpha$-form has a density $7.475 \mathrm{~g} / \mathrm{cm}^{3}$ (card 32-0637 [19]). The hightemperature $\beta$-form has a density $7.257 \mathrm{~g} / \mathrm{cm}^{3}$ (card 33-0887 [19]).

The energy fixed in the high-temperature (hardened form) is accumulated in electrons. During annealing the energy dissipates and the material density increases.

The heat expansion of materials can be explained by the fixation of excess energy in electrons.

On the level of interatomic interaction the material structure determining differences in its properties with an unchanged chemical composition undergoes changes in the system energy content [20]-[22].

The information obtained by the proposed method can be used for the control of the state of pelletized heatproof nickel alloy grade EP741NP when diagnosing its quality.

The conducted experiments may serve as evidence that the alloy obtained using the pellet technology is thermodynamically non-equilibrium. During heat treatment the alloy structure changes, it loses previously accumulated energy and passes into more thermodynamically stable equilibrium state.

\section{Conclusions}

1) It was experimentally confirmed that the structural changes of a material have an effect on the results of the atomic emission spectroscopy of solid samples.

2) It was established that the differences of the signals in spectral analysis under equal conditions of excitation and graduation can be used to describe structural change in a study specimen.

3) A calculation method was proposed which allows evaluating the EP741NP alloy structure using signal analysis during atomic emission spectroscopy.

4) The proposed method for alloy structure characterization makes possible to consid- 
er local interatomic interactions between atoms of alloying elements with the matrix metal.

\section{References}

[1] Molchan, N.V. and Fertikov, V.I. (2012) A Method for Aluminum Alloy Structure Inspection. Patent RF 2442139.

[2] Molchan, N.V. and Fertikov, V.I. (2013) A Method to Control Structure of Titanium Alloy. Patent RF 2486494.

[3] Molchan, N.V. and Fertikov, V.I. (2014) Control over Steel Structure. Patent RF 2518292.

[4] Molchan, N.V. (2014) A Method of Brass Structure Control. Patent RF 2531339.

[5] Molchan, N.V., Seguru, G.V. and Fertikov, V.I. (2015) Control Method of Magnesium Alloy Structure. Patent RF 2558632.

[6] Molchan, N.V., Eliseev, D.S., Seguru, G.V. and Fertikov, V.I. (2016) A Method of Controlling Structure of Nickel Alloy. Patent RF 2581077.

[7] Sirotkin, O.S. (2011) The Princiles of Innovative Material Science. INFRA-M, Moscow.

[8] Molchan, N.V. and Fertikov, V.I. (2015) Determination of Concentration of Electrons for Description of the Structure of Materials, with Sulfides as an Example. Journal of Materials Sciences ad Applications, 1, 38-44.

[9] Molchan, N.V. and Fertikov, V.I. (2012) Control of the Structure of an Aluminum Alloy by Atomic Emission Spectroscopy. Russian Metallurgy (Metally), 5, 428-430. http://dx.doi.org/10.1134/S0036029512050114

[10] Molchan, N.V., Polkin, I.S. and Fertikov, V.I. (2014) Ability to Control a Titanium-Alloy Structure by Atomic-Emission Spectroscopy. Journal of Applied Spectroscopy, 2, 169-173. http://dx.doi.org/10.1007/s10812-014-9905-x

[11] Buravlev, Y.M. (2000) Atomic Emission Spectroscopy of Metals and Alloys. DonNU, Donetsk.

[12] Martin, J. (2007) Concise Encyclopedia of the Structure of Materials. Elsevier Limited, Amsterdam.

[13] The Certificate on the $30^{\text {th }}$ Reference Standard Set for Spectral Analysis of Steels Types R9 and R18. (1958) Sverdlovsk.

[14] Buravlev, Y.M., Grikit, I.A., Nikitina, O.A. and Ivanov, A.I. (1988) Methods of Spectral Analysis of Metals and Alloys. Tekhnika, Kiev.

[15] Buravlev, Y.M. (1963) Effect of Structure on the Results of Spectrum Analysis of Alloys. Metallurgizdat, Moscow.

[16] Glansdorf, P. and Prigogine, I. (1971) Thermodinamic Theory of Structure, Stability and Fluctuations. John Wiley \& Sons, New York.

[17] Müller, P., Neumann, P. and Storm, R. (1979) Tafeln der mathematischen Statistik. VEB Fachbuchverlag, Leipzig.

[18] Emsly, J. (1991) The Elements. Clarendon Press, Oxford.

[19] International Centre for Diffraction Data. JCPDS PCPDFWIN, V.2.03 (2002).

[20] Mosichev, V.I., Nilolaev, G.I. and Kalinin, B.D. (2006) Metals and Alloys. Analysis and Study. Atomic Emission, Atomic Absorption and X-Ray Fluorescence Analysis. Reference Guide. Professional, St-Petersburg.

[21] Molchan, N.V. and Fertikov, V.I. (2011) Compressibility of Substances and Dimensions of 
Atoms. Material Science, 171, 2-6.

[22] Arzamasov, B.N., Makarova, V.I., Mukhin, G.G., Ryzhov, N.M. and Silaev, V.I. (2005) Material Science. Publishing House of Bauman MGTU, Moscow.

\section{Submit or recommend next manuscript to SCIRP and we will provide best service} for you:

Accepting pre-submission inquiries through Email, Facebook, LinkedIn, Twitter, etc. A wide selection of journals (inclusive of 9 subjects, more than 200 journals)

Providing 24-hour high-quality service

User-friendly online submission system

Fair and swift peer-review system

Efficient typesetting and proofreading procedure

Display of the result of downloads and visits, as well as the number of cited articles

Maximum dissemination of your research work

Submit your manuscript at: http://papersubmission.scirp.org/ 